\title{
Sad tale of an endangered zoo
}

Peaceful English contentment has been disturbed by rumours that the London Zoo may have to be closed later in the year, but neither the reasons for the sudden fuss nor the need for such a catastrophe are clear.

WHEN the world is full of people worrying about the future of other than the human species, how can the London Zoo be in danger of commercial failure? This week, the zoo has been putting it about that it may have to close later in the year, depending on the outcome later in the week of a further appeal for funds to the British government. At one stage, there was even a suggestion (quickly denied) that many of the 8,000 animals at the London Zoo might have to be killed, or 'put down' as the British say.

The most charitable explanation for this state of affairs is that animal-lovers are no longer willing to pay to see the objects of their affection locked up in cages, but that is at best a poor explanation, supposing as it does that the fault lies with the customer. It is easier to believe that the London Zoo, which has been struggling with deficits for years, has with equal consistency failed to attract its natural customers and to provide them with the incentive to return.

A zoo, for better or worse, is a commercial operation, which is not to say that it is simply a business. Making it possible for people who mostly live in Britain to see exotic animals is a public service, a way of reminding mostly urban dwellers of the diversity of the life beyond the limits of their subway networks and of the phenotypic inventiveness of the animal genome, appropriately shuffled. The difficulty is that, to keep animals in a zoo, it is necessary to feed them artificially and to pay keepers to do the work. That is where commercial reality intrudes on public service.

It is natural that most respectable zoos should have been founded by naturalists or zoologists, and that the search for commercial viability has often been painful and uncertain. Often, the search turns out to be fruitless. The London Zoo, which claims to be the oldest of its kind, seemed to have been permanently saved two years ago, when the British Department of the Environment provided it with a capital endowment of $£ 10$ million. But in a recession year, that turns out to be insufficient, and the begging bowl is out again. The London zoos - there are two, one in Central London and one at a country site called Whipsnade Park, thirty miles north have let the painful search for viability drag on for too long.

What does London lack that San Diego has? The San Diego Zoo (see Nature 349, 457; 7 February 1991) is zoologically respectable, even distinguished in projects such as the return of the condor to the wild, has a financial turnover roughly ten times that of the London Zoo (excluding Whips- nade), but derives only two per cent of its income from public sources (a property tax levied by the City of San Diego). One of the most signicant items in San Diego's profit and loss account is the income derived from family memberships in the zoo. The largest is the income from the sale of goods from the zoo's array of shops.

San Diego stays more or less in financial balance - it has no choice - but in the most recent financial year, the city-centre London Zoo had an income of $£ 4.2$ million and made a trading loss of $£ 1.9$ million. For the British enterprise as a whole, which includes both zoo sites and the research institute called the Institute of Zoology, the trading income amounted to $£ 6.9$ million, the cost of running the operation was $£ 11.8$ million and the loss amounted to no less than $£ 4.9$ million. (To be fair, the services such as these in London are contracted out to operating companies, and only the nett amounts of profit and loss are shown in the zoos' accounts.) Even so, for every $£ 1$ taken in admission fees, the enterprise had to draw down its investments by nearly $£ 0.70$.

That sounds dangerously like carelessness, especially because the news of the deficit followed almost on the heels of public excitement at a proposal that the city-centre zoo should take in an extra slice of the city park in which it is located so as to enlarge itself. And the truth is that it is carelessness of a kind. Part of the present trouble is that the recession has cut people's willingness to pay admission fees and then to spend money on other things when they are inside one or other of the London zoos, but it is careless to behave as if such evil luck can be countered by seeking sponsorship from commercial companies which are likely themselves to be more directly exposed to recessionary forces than even the zoos' admission turnstiles.

The only sure remedy in such circumstances is to spend less, but the zoos' staff at both sites increased between 1989 and 1990 by ten per cent (and its total salary bill by 25 per cent). No doubt the increases were desirable, but would it not have been better to postpone them than to risk closing one or other of the sites? That may seem a harsh and shortsighted view, but it is what passes for commercial reality.

So what should be done? To the question what does London lack that San Diego enjoys should be answered, first, climate (which tempts people to picnic at the zoo) and, second, foresight and imagination (which has made it worthwhile to foster the membership scheme over a period of half a century). But the question can also be answered when asked the other way round; London's climate may leave something to be desired, but the city-centre zoo does enjoy 42 acres of central London, a mere bus ride from the places thronged by tourists most times of the year? And it is at the centre of a conurbation of 20 million people, ten times as great as that from which the catchment area from which San Diego's family memberships are drawn.

The first need is that the zoos (or the Zoological Society of London, which owns them) should resolve to keep both sites going, however painful the economies required for the purpose. If necessary, the Institute of Zoology, which exists mainly for research on members of the animal collection, but which also has an important conservation and field programme, should be spun off to some other institution or, at the worst, closed altogether. Without the zoos, it would not (and perhaps could not) exist. Why keep it going when its continuation threatens the survival of the zoos on which its own longterm existence hangs to the tune of more than $£ 1$ million a year? That sounds rough talk, but is there a choice?

Keeping the city-centre site in being is essential if the zoos are ever to make the claim on the attention of the general public from which their core support must eventually be drawn, but that does not mean that the same complement of animals must remain there indefinitely. Fewer animals in the city zoo might enable a smaller staff to show them off more interestingly, and more in keeping with more enlightened views of how animals in captivity should be kept. The notion of a commuter zoo in which some animals are visitors from the distant suburbs should not be scorned.

The zoos must also learn more about the markets, whose downturn has caused such tribulation, than they seem to know at present. At present they do little to tell their potential customers of what exhibits are particularly interesting, and when. The potential benefits of a general membership scheme (not just for zoologists and their partners) have not been appreciated, but would handsomely reward sustained encouragement (even if that meant breaking down some of the barriers between professionals and the unqualified masses). And if the worst comes to the worst, the market would always allow the zoos to put their own operation out to commerciual tender. It would be surprising if there were no takers, even on the most onerous conditions.

John Maddox 